\title{
El papel de la Investigación en el avance de la ingeniería ${ }^{1}$
}

La investigación es uno de los motores que impulsa el desarrollo de las ciencias y de ciertas disciplinas como la Ingeniería, ésta última constituye el factor que impulsa el crecimiento de la sociedad. Estas afirmaciones tienen sustento en testimonios de entidades como la UNESCO, quien manifiesta en su reporte titulado "Engenieering: Issues challenges and opportunities for development", que la ingeniera es la única disciplina capaz potencializar el desarrollo de un pais: es la única disciplina que puede romper las brechas sociales y económicas entre los países desarrollados y los países subdesarrollados (UNESCO, 2010). La responsabilidad del desarrollo tecnológico demandado por nuestra sociedad se atribuye a las ingenierías; sectores tan diversos y disimiles como el transporte, la industria petrolera, la energía, la industria química, la tecnología en telecomunicaciones y la nanotecnología, por nombrar solo algunos de los más importantes. Es irónico entonces que el interés en el estudio de la ingeniera entre los jóvenes esté disminuyendo, especialmente en los paises en desarrollo. Este fenómeno invita al aumento de esfuerzos en la formación y el desarrollo de la ingeniería no sólo para el crecimiento de la producción sino también para incrementar el impacto en las actividades académicas e investigativas, y así lograr protección y optimización de los recursos naturales.
Un hecho indudable es que las olas de innovación han impulsado y transformado la disciplina de la ingenieria. El principio de esta evolución ha sido enmarcada por las necesidades de cada época de la sociedad, la evolución de la ingeniería, así como de otras tantas ciencias y disciplinas establece sus orígenes en el desarrollo de conocimientos como la tecnología del agua, el poder del vapor, la máquina de combustión interna y la química, la electrónica y la aviación, la era digital y la tecnología de la información. En la actualidad, la sociedad se encuentra abordando la sexta ola de innovación en donde los grandes protagonistas son la sostenibilidad, la química verde, las energías renovables y la nanotecnología.

La ingeniería está compuesta por una serie de conocimientos, leyes, teorías y conceptos suministrados por las ciencias, por otra parte, la tecnologia proporciona herramientas como insumo para el desarrollo de productos, servicios básicos y beneficios, para suplir las necesidades de la sociedad a partir de los recursos que ella misma y el entorno natural le suministran. Las diferentes etapas de la investigación se revelan de manera similar: existe una etapa de investigación básica, una etapa de desarrollo tecnológi1co y finalmente una etapa de innovación que finalmente incorpora productos a la sociedad después de un proceso investigativo

1 The United Nations Educational, Scientific and Cultural Organization, (UNESCO, 2010). Engineering: Issues, Challenges and Opportunities for Development. Recuperado en: http://unesdoc.unesco.org/images/0018/001897/189753e.pdf 
que puede tomar diferentes lapsos de tiempo, en algunos casos toma años e incluso décadas. Esta última etapa ha sido desarrollada principalmente por la ingeniería que ha demostrado, una vez más, la importancia de esta disciplina para el desarrollo de la sociedad.

El aumento en el número de ingenieros en una sociedad puede constituir un factor eficaz en la reducción de la brecha social y económica. La importancia de este incremento radica en los cambios que la disciplina está sufriendo, la ingeniería a través del tiempo se ha convertido en una ciencia interdisciplinar, principalmente por la incorporación de las ciencias básicas además de la incorporación de nuevos campos del co- nocimiento, nuevas tecnologías y nuevas ramas de la ingeniería. Las nuevas formas de hacer ingeniería demandan cada vez más competencias investigativas en los profesionales, así como mayor capacidad de liderazgo, ingenio, innovación e incorporación de conceptos novedosos. El horizonte de la ingeniería nunca antes había sido tan complejo y fascinante. Como una forma de participar en ese panorama, la Universidad de América prepara esta revista, consciente de que cada uno de los artículos aquí incluidos tienen, además de su importancia y rigor académi$\mathrm{co}$, un impacto social indudable.

\section{Ph. D. Cesar Augusto Quiñones Segura} Docente Investigador 